\title{
Age-related changes in radiation-induced micronuclei among healthy adults
}

G. Joksić, S. Petrović and Ž. Ilić
"Vinča" Institute of Nuclear Sciences, Belgrade, Yugoslavia

Correspondence
G. Joksić
"Vinča" Institute of
Nuclear Sciences
P.O. Box 522
11000 Belgrade
Yugoslavia
Fax: +381-1125-3967
E-mail: gjoksic@vin.bg.ac.yu
Research supported by the
Ministry of Science and
Technology of Serbia,
Project 1991.
. . . . . . . . . . . . . . . . . . . .

Received February 4, 2003 Accepted March 22, 2004

\begin{abstract}
The aim of the present study was to establish the extent of in vitro radioresponse of lymphocytes among 62 healthy adults of both genders and to estimate the distribution of baseline micronuclei and radiosensitivity among individuals of the study population using the cytochalasin block micronucleus test. A younger study group consisted of 10 males (mean age, 22.4 years; range, 21-27) and 12 females (mean age, 24.8 years; range, 20-29), whereas an older study group consisted of 18 males (mean age, 35.1 years; range, 30-44) and 22 females (mean age, 38.5 years; range, 30-48). For evaluation of radiosensitivity blood samples were irradiated in vitro using ${ }^{60} \mathrm{Co} \gamma$-ray source. The radiation dose employed was $2 \mathrm{~Gy}$, the dose rate $0.45 \mathrm{~Gy} /$ $\mathrm{min}$. The study revealed a significant gender effect on baseline micronuclei favoring females $(\mathrm{Z}=3.25, \mathrm{P}<0.001)$, while yields of radiation-induced micronuclei did not differ significantly $(\mathrm{Z}=0.56, \mathrm{P}<$ $0.56)$ between genders. The distribution of baseline micronuclei among the individuals tested followed Poisson distribution in both study groups and in both genders, whereas the distribution of radiosensitivity among individuals of the older study group did not fulfill Poisson expectations (Kolmogorov-Smirnof test, $\mathrm{P}<0.01$ ). In contrast to a nonsignificant difference in radiosensitivity between males and females of the same age group $(Z=1.97, P<0.56)$, a statistically significant difference in radiosensitivity between younger and older group for both genders was found $(Z=3.03, P<0.03)$. Since the individuals tested were healthy, the observed variability in radiation response is considered to be an early effect of ageing.
\end{abstract}

Key words

- Human lymphocytes

- Baseline micronuclei

- Radiosensitivity

- Ageing

\section{Introduction}

The assay most frequently used in genotoxicity testing is the induction of chromosomal aberrations. However, the in vitro micronucleus test is also suitable for the evaluation of genotoxicity (1-7) and is applied to human biomonitoring $(8,9)$. Since radiation- induced micronuclei show a clear dependence on radiation dose and its quality (1014), the micronucleus assay can be applied as a biological dosimeter.

Micronuclei are chromatin-staining structures in the cytoplasm surrounded by a membrane without any detectable link to the cell nucleus (15). They are formed by exclusion 
of whole chromosomes or chromatin fragments during cell division. Micronuclei are visualized using different staining techniques (Giemsa or fluorescent) and their frequency is quantified microscopically.

The simplicity of micronucleus scoring makes this test very attractive when large numbers of cells must be analyzed. The assay has been recently applied to estimate radiosensitivity and to the investigation of individual variability in response to ionizing radiation (16-18).

In a previous study by our group (19), the cytochalasin B-blocking micronucleus test was used to estimate the radiosensitivity of human lymphocytes from males of different ages (18, 45 and 65 years on average). The results showed a slight increase in baseline micronuclei with age, and wide variation in number of radiation-induced micronuclei in the middle-aged group. A subsequent study (20) highlighted a significant gender effect on baseline micronuclei, the lack of statistical differences between genders in the yield of radiation-induced micronuclei, and marked variability in radiation response among individuals of the same age group. The likelihood of expressing sensitivity was correlated with the ability of cells to proliferate in vitro more than with the incidence of radiation-induced micronuclei per micronucleated cell.

The objective of the present study was to determine the extent of sensitivity of the in vitro radioresponse of lymphocytes from healthy adults of both genders aged 22 to 40 years and to estimate the baseline distribution of micronuclei and radiosensitivity among the individuals of tested population using the cytochalasin block micronucleus test.

\section{Material and Methods}

\section{Subjects}

The study was conducted on 62 healthy individuals of Red Cross volunteers, 28 men and 34 women not exposed occupationally to known mutagenic agents. Blood samples were obtained during a routine health checkup only from healthy persons selected by a physician. The subjects were divided into two age groups as shown in Table 1. In the male group, 4 of 28 subjects were smokers and in the female group, 6 of 34 subjects were smokers.

\section{Irradiation}

Blood samples were obtained by venipuncture using heparinized syringes and needles. Two hours after blood collection, a 3 -ml aliquot of each sample was added to a sterile plastic test-tube placed in a $15 \times 15$ $\mathrm{cm}$ Plexiglas container and irradiated using a ${ }^{60} \mathrm{Co} \gamma$-ray source. The radiation dose employed was $2 \mathrm{~Gy}$, the dose rate $0.45 \mathrm{~Gy} / \mathrm{min}$, the dimensions of the radiation field were 20 x $20 \mathrm{~cm}$, and the distance from the source was $74 \mathrm{~cm}$. Blood samples were irradiated at room temperature and cultured $1 \mathrm{~h}$ after irradiation and non-irradiated samples were used as controls.

\section{Micronucleus analysis}

Micronucleus analysis was carried out on blood lymphocyte cultures stimulated with phytohemagglutinin $(2.4 \mu \mathrm{g} / \mathrm{ml}$, Gibco BRL). Whole blood $(0.5 \mathrm{ml})$ was added to $5 \mathrm{ml}$ RPMI-1640 medium supplemented with 15\% calf serum and lymphocytes were incubated at $37^{\circ} \mathrm{C}$. Cytokinesis was blocked by the method of Fenech (1). Cytochalasin B was added to the cultures at a final concentration of $4 \mu \mathrm{g} / \mathrm{ml} 44 \mathrm{~h}$ after stimulation with phytohemagglutinin. Seventy-two hours after culture initiation, cells were fixed in methanol: acetic acid (3:1) after 5 min of mild hypotonic treatment $(0.56 \% \mathrm{KCl}+0.9 \% \mathrm{NaCl}$ mixed in equal volumes). Slides were airdried and stained with $2 \%$ alkaline Giemsa. An irradiated blood sample and a non-irradi- 
ated control were analyzed for each subject. For each sample 1000 binucleated cells were scored and micronuclei were recorded using a Zeiss microscope (400 or 1000X magnification when necessary).

\section{Statistical analysis}

Data were analyzed statistically using the software package "Statistic" for Windows 9.8, version 5.5. The Wilcoxon matchedpair test was employed. The distribution of spontaneously occurring and radiation-induced micronuclei regarding gender and age was assessed using the Kolmogorov-Smirnof test.

\section{Results}

The results of micronucleus analysis are presented in Table 1 and Figures 1 to 4 . For evaluation of radiosensitivity, baseline micronuclei were subtracted from those recorded for irradiated samples, representing the level of radiation-induced micronuclei.

In the male group there was no statistically significant difference in baseline micronuclei between the two age groups (Wilcoxon matched-pair test, $\mathrm{Z}=0.05, \mathrm{P}<0.95$ ) but a statistically significant difference in the yields of radiation-induced micronuclei was observed between the two age groups of males (Wilcoxon matched-pair test, $\mathrm{Z}=3.05$, $\mathrm{P}<0.03)$.

In the female group, no significant difference in baseline micronuclei was observed between the two age groups (Wilcoxon matched-pair test, $\mathrm{Z}=0.31, \mathrm{P}<0.75)$, whereas the yields of radiation-induced micronuclei differed significantly (Wilcoxon matched-pair test, $\mathrm{Z}=3.05, \mathrm{P}<0.002$ ).

Considering the male and female group as a whole, a significant difference in baseline micronuclei was observed $(Z=3.25, P<$ 0.001 ), while yields of radiation-induced micronuclei did not differ significantly $(\mathrm{Z}=$ $0.56, \mathrm{P}<0.56$ )
The baseline micronucleus distribution for males and females of both study groups did not differ significantly from a Poisson distribution (Kolmogorov-Smirnof test, $\mathrm{d}=$

Table 1. Frequency of baseline and radiation-induced micronuclei in healthy adults of both genders.

\begin{tabular}{lccc}
\hline & Group I & Group II & Total \\
\hline Total individuals per group & 22 & 40 & 62 \\
Sex & & & \\
$\quad$ Male & 10 & 18 & 28 \\
$\quad$ Female & 12 & 22 & 34 \\
Smokers & & & \\
$\quad$ Yes & 7 & 3 & 10 \\
$\quad$ No & 15 & 37 & 52 \\
Median age of group (years) & 23.6 & 36.8 & 32.1 \\
Median age (males; females) & $22.4 ; 24.8$ & $35.1 ; 38.5$ & $30.1 ; 34.1$ \\
Age range (males; females) & $21-27 ; 20-29$ & $30-44 ; 30-48$ & $21-24 ; 20-48$ \\
Micronucleus count & & & \\
$\quad$ Baseline & & & \\
$\quad$ Male & $6.9 \pm 3.03$ & $7.62 \pm 2.91$ & $7.35 \pm 2.92$ \\
$\quad$ Female & $9.83 \pm 2.36$ & $10.33 \pm 3.04$ & $10.02 \pm 2.79$ \\
$\quad$ Total & & & \\
Radiation-induced & & & \\
$\quad$ Male & & & \\
$\quad$ Female & $220.10 \pm 13.51$ & $206.78 \pm 73.72$ & $211.53 \pm 59.37$ \\
$\quad$ Total & $225.0 \pm 22.86$ & $205.54 \pm 46.18$ & $209.52 \pm 44.52$ \\
& $222.77 \pm 18.92$ & $206.10 \pm 59.31$ & $213.10 \pm 49.82$ \\
\end{tabular}

Micronucleus data are reported as mean number \pm SD of micronuclei per 1000 binucleated cells.

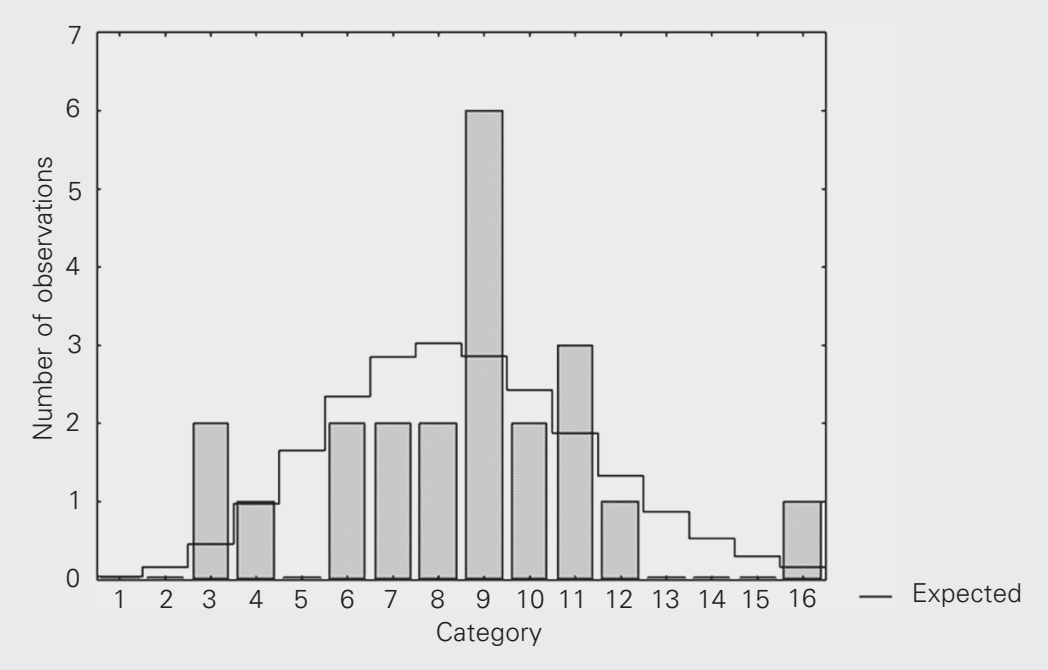

Figure 1. Distribution of baseline micronuclei among individuals aged on average 23.6 years (Kolmogorov-Smirnof test, $d=0.11$, nonsignificant). 

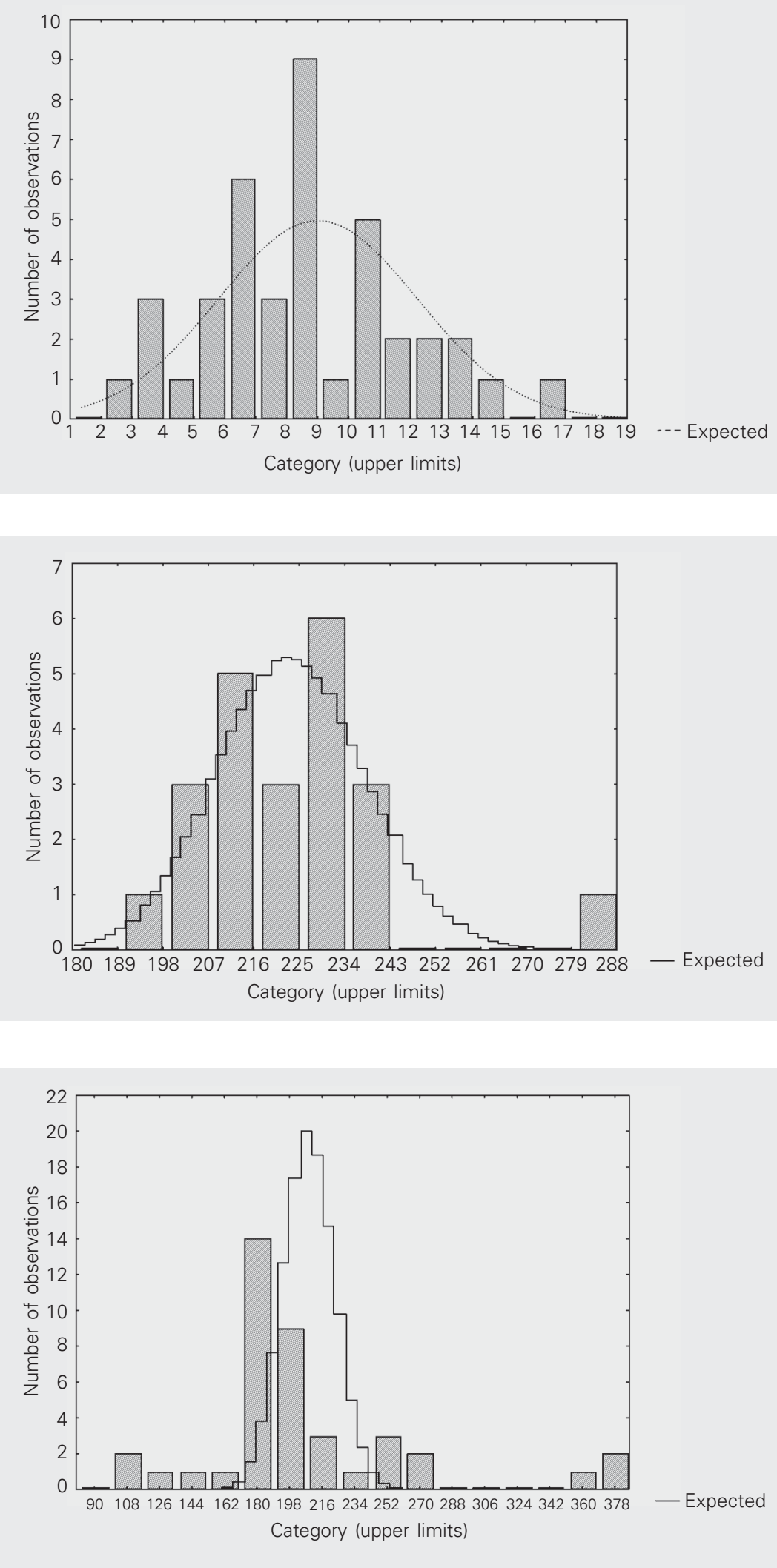

Figure 2. Distribution of baseline micronuclei among individuals aged on average 36.8 years (KolmogorovSmirnof test, $d=0.15$, nonsignificant).

Figure 3. Distribution of radiosensitivity among individuals aged on average 23.6 years (KolmogorovSmirnof test, $d=0.68$, nonsignificant).

Figure 4. Distribution of radiosensitivity among individuals aged on average 36.8 years (KolmogorovSmirnof test, $d=0.36, P<0.01$ ). 
0.11 and 0.15 ; Figures 1 and 2). The distribution of radiosensitivity among individuals of the younger study group did not differ significantly and also followed Poisson expectation (Kolmogorov-Smirnof test, $\mathrm{d}=0.68$; Figure 3 ). In contrast to the younger study group, we found a significant difference between the yields of radiation-induced micronuclei and the Poisson distributions in the group of older individuals (KolmogorovSmirnof test, $\mathrm{d}=0.36, \mathrm{P}<0.01$; Figure 4).

\section{Discussion}

Accumulated mutations seem to be the main cause of accelerated ageing or cancer. Many enzymes and regulatory proteins are devoted to the repair of DNA damage because unrepaired DNA damage can lead to mutations. Recent studies have pointed out that more than 120 repair genes are involved in the repair of DNA damage (21), suggesting that it might be more practical to study "repair phenotype" than to try to unravel or predict phenotype from complete genotypic information. Repair phenotype can be easily recognized by provoking cell radioresponse in vitro using a simple test such as the cytochalasin block micronucleus test (22).

A significant gender effect on baseline micronuclei favoring females has been previously reported (23) and confirmed in recent large-scale studies $(24,25)$. On this basis, we may hypothesize that $\mathrm{X}$-chromosomes play an important role in the occurrence of micronuclei by interaction of their products with receptors located on the nuclear membrane and with proteins of the spindle apparatus. Some studies demonstrated that an inactive $\mathrm{X}$-chromosome is preferentially included in the micronuclei, suggesting that $\mathrm{X}$ chromosome hypodiploidy in aging women is a related phenomenon.

Our earlier study showed a significant gender effect on the baseline level of micronuclei favoring females, which was confirmed in the present study. In addition to determining the baseline level of micronuclei, we estimated radiation-induced sensitivity in two groups of healthy adults of both genders aged 22 and 40 years. Several important results were obtained: i) the distribution of baseline micronuclei followed Poisson distributions in both study groups of both genders, ii) there was a nonsignificant difference in baseline micronuclei between the two age groups of both genders, iii) marked variability in radiation-response was observed among individuals near 40 compared to those near 23 years old, iv) the distribution of radiosensitivity among older individuals did not follow Poisson expectations, v) in contrast to a nonsignificant difference in baseline micronuclei between the young ( 23 years) and older (37 years) groups, radiosensitivity differed significantly between older members of both genders and young members.

Variability in radiosensitivity of a healthy human population might be expected to result from a cumulative effect of the minor differences in the efficiency of genes involved in the response to ionizing radiation, from individual susceptibility factors related to micronutrient status, or from genetic polymorphisms of enzymatic defense against radiation-induced toxicity. Genetic polymorphisms may be important in explaining the individual variation in radioresponse observed in different tests with human cells (26). Our earlier study demonstrated that individual sensitivity to ionizing radiation is inversely correlated with the activities of antioxidant enzymes such as cytosolic and mitochondrial superoxide dismutases (27). An important finding of this study was that the distribution of radiosensitivity in the group of 40-year-old individuals on average did not follow Poisson expectations. The marked individual variability observed in this group ranged from a resistant (113-114 micronuclei per 1000 binucleated cells) to sensitive radioresponse (364-378 micronuclei per 1000 binucleated cells). This obser- 
vation could be explained by ageing, due to cumulative defects in the efficiency of repair genes or of antioxidant defense mechanisms. Reduced repair efficiency and accumulated point mutations due to ageing certainly could increase the levels of radiationinduced micronuclei. A sensitive radioresponse was not observed in the younger subjects of both genders, possibly reflecting differences in repair of damaged DNA and the ability to pause while the damage is repaired. This type of "phenotype repair" is seen as a consequence of accelerated ageing, which led to micronucleus distribution diverging from Poisson expectations. Ageing is usually followed by disturbances in micronutritient status and accumulated point muations of repair genes: folate and vitamin $\mathrm{B}_{12}$ concentrations are particularly impor- tant determinants of micronucleus frequency $(28,29)$. Recent studies on men aged 50-70 years have confirmed these observations $(30,31)$.

Variability in radioresponse suggests that individual radiosensitivity might play a crucial role in radiotherapy. Knowledge of a patient's individual radiosensitivity before radiotherapy could be of help in planning the most appropriate clinical treatment.

In the near future, new information will be obtained on polymorphisms affecting DNA repair and genome integrity, which are probably of special importance in modulating radiation effects. Fully understanding the mechanisms of radioresponse and the possibility to modulate it is expected to improve the applicability of the micronucleus assay to individualized radiotherapy schemes.

\section{References}

1. Fenech M (1993). The cytokinesis-block micronucleus technique: a detailed description of the method and its application to genotoxicity studies in human populations. Mutation Research, 285: 35-44.

2. Rimoldi R, Miller AC, Freeman SE \& Samid D (1991). DNA damage in cultured human skin fibroblasts exposed to excimer laser radiation. Journal of Investigative Dermatology, 96: 898-902.

3. Degen GH (1993). SEMV cell cultures: a model for studies of prostaglandin-H synthase-mediated metabolism and genotoxicity of xenobiotics. Toxicology Letters, 67: 187-200.

4. Matsuoka A, Yamazaki N, Suzuki T, Hayashi M \& Sofuni T (1992). Evaluation of the micronucleus test using a Chinese hamster cell line as an alternative to the conventional in vitro chromosomal aberration test. Mutation Research, 272: 223-236.

5. Stopper H, Korber C, Schiffmann D \& Caspary WJ (1993). Cell-cycle dependent micronucleus formation and mitotic disturbances induced by 5 -azacytidine in mammalian cells. Mutation Research, 300: 165-177.

6. Miller BM, Pujadas E \& Gocke E (1995). Evaluation of the micronucleus test in vitro using Chinese hamster cells: results of four chemicals weakly positive in the in vivo micronucleus test. Environmental and Molecular Mutagenesis, 26: 240-247.

7. Rosin MP (1992). The use of the micronucleus test on exfoliated cells to identify anti-clastogenic action in humans: a biological marker for the efficacy of chemopreventive agents. Mutation Research, 267: 265-276.

8. Natarajan AT, Boei JJ, Darroudi F, Van Diemen PC, Dulout F, Hande MP \& Ramalho A (1996). Current cytogenetic methods for detecting exposure and effects of mutagens and carcinogens. Environmental Health Perspectives, 104 (Suppl 3): 445-448.

9. Fenech M, Holland N, Chang WP, Zeiger E \& Bonassi S (1999). The
Human Micronucleus Project - An international collaborative study on the use of the micronucleus technique for measuring DNA damage in humans. Mutation Research, 428: 271-283.

10. Ramalho A, Sunjevaric I \& Natarajan AT (1988). Use of the frequencies of micronuclei as quantitative indicators of X-ray induced chromosomal aberrations in human peripheral blood lymphocytes: Comparison of two methods. Mutation Research, 207: 141-146.

11. Köeteles GJ (1996). Biological dosimetry. Lecture notes for the IRPA 9 Refresher Course, R-06. International Congress on Radiation Protection, April 14-19, Vienna, Austria, 1-40.

12. Galloway SM, Sofuni T, Shelby MD et al. (1997). Multilaboratory comparison of in vitro tests for chromosome aberrations in $\mathrm{CHO}$ and $\mathrm{CHL}$ cells tested under the same protocols. Environmental and Molecular Mutagenesis, 29: 189-207.

13. Palitti F (1998). Mechanisms of the origin of chromosomal aberrations. Mutation Research, 404: 133-137.

14. Fenech M (1991). Optimisation of micronucleus assays for biological dosimetry. Progress in Clinical and Biological Research, 372: 373-386.

15. Fenech M \& Morely AA (1985). Measurement of micronuclei in Iymphocytes. Mutation Research, 147: 29-36.

16. Murnane JP \& Kapp LN (1993). A critical look at the association of human genetic syndrome with sensitivity to ionizing radiation. Seminars in Cancer Biology, 246: 629-634.

17. West CM, Scott D \& Peacock JH (1994). The Association for Radiation Research First Workshop: report. Normal cell radiosensitivity: clinical application in predicting response to radiotherapy and cancer predisposition. Westlakes Research Institute, Cumbria, UK, March 21-23, 1994. International Journal of Radiation and Biology, 66: $231-234$. 
18. Scott D, Barber JB, Levine EL, Burrill W \& Roberts SA (1998). Radiation-induced micronucleus induction in lymphocytes identifies a high frequency of radiosensitivity cases among breast cancer patients: a test for predisposition? British Journal of Cancer, 77: 614-620.

19. Joksić G, Nikolić M \& Spasojević-Tišma V (1997). Radiosensitivity of different aged human lymphocytes following electron irradiation in vitro. Neoplasma, 44: 117-121.

20. Joksić G, Petrović-Novak A, Stanković M \& Kovačević M (1999). Radiosensitivity of human lymphocytes in vitro correlates more with proliferative ability of cells than with the incidence of radiationinduced damages of the genome. Neoplasma, 46: 40-49.

21. Wood RD, Mitchell M, Sgouros J \& Lindahl T (2001). Human DNA repair genes. Science, 29: 1284-1289.

22. Fenech M (2002). Biomarkers of genetic damage for cancer epidemiology. Toxicology, 181-182: 411-416.

23. Fenech M, Neville S \& Rinaldi J (1994). Sex is an important variable affecting spontaneous micronucleus frequency in cytokinesis blocked lymphocytes. Mutation Research, 313: 203-207.

24. Hando JC, Nath J \& Tucker JD (1994). Sex chromosomes, micronuclei and aging in women. Chromosoma, 103: 186-192.

25. Tucker JD, Nath J \& Hando JC (1996). Activation status of the X chromosome in human micronucleated lymphocytes. Human Ge- netics, 97: 471-475.

26. Rothfuss A, Schutz P, Bochum S, Volm T, Eberhardt E, Kreienberg $R$, Vogel W \& Speit G (2000). Induced micronucleus frequencies in peripheral blood lymphocytes as a screening test for carriers of a BRCA1 mutation in breast cancer families. Cancer Research, 60: 390-394.

27. Joksić G, Pajović SB, Stanković M, Pejić S, Kasapović J, Cuttone G, Calonghi N, Masotti L \& Kanazir DT (2000). Chromosome aberrations, micronuclei and activity of superoxide dismutases in human lymphocytes after irradiation in vitro. Cellular and Molecular Life Sciences, 57: 842-850.

28. Fenech M, Aitken C \& Rinaldi J (1998). Folate, vitamin B12, homocysteine status and DNA damage in young Australian adults. Carcinogenesis, 19: 1163-1171.

29. Fenech M, Dreosti I \& Aitken C (1997). Vitamin-E supplements and their effect on vitamin-E status in blood and genetic damage rate in peripheral blood lymphocytes. Carcinogenesis, 18: 359-364.

30. Fenech M, Dreosti IE \& Rinaldi JR (1997). Folate, vitamin B12, homocysteine status and chromosome damage rate in lymphocytes of older men. Carcinogenesis, 18: 1329-1336.

31. Lenton KJ \& Greenstock CL (1999). Ability of human plasma to protect against ionising radiation is inversely correlated with age. Mechanisms of Ageing and Development, 107: 15-20. 